\title{
Role of biomarkers in the clinical management of glioblastomas: what are the barriers and how can we overcome them?
}

\author{
Kerrie L. McDonald *, Grace Aw and Paul Kleihues \\ Lowy Cancer Research Centre, Prince of Wales Clinical School, University of New South Wales, Kensington, Australia
}

\section{Edited by:}

Patrick Wen, Dana-Farber Cancer

Institute, USA

Reviewed by:

Lakshmi Nayak, Dana-Farber Cancer Institute, USA

Eudocia Lee, Dana Farber Cancer Institute, USA

Mikael L. Rinne, Dana-Farber Cancer Institute, USA

\section{*Correspondence}

Kerrie L. McDonald, Level 2, Lowy Cancer Research Centre, University of New South Wales, Kensington,

NSW 2052, Australia.

e-mail: k.mcdonald@unsw.edu.au
Thousands of articles describing biomarkers predictive of treatment and prognostic of survival in cancer have been published, yet only a handful of biomarkers are currently used routinely in the clinic. Biomarkers need to be analytically standardized, validated, and clinically useful. This review will address the challenges and ways in which we can improve our discovery and translation of prospective biomarkers from the lab into validated diagnostic tests with a specific focus on patients diagnosed with glioblastoma and MGMT promoter methylation status. There has been long-held enthusiasm to use MGMT promoter methylation as a predictive biomarker for patients treated with the alkylating agent, temozolomide; however in the majority of centers around the world, this has not yet transpired.

Keywords: biomarkers, treatment response, glioblastoma, MGMT, tumor heterogeneity

\section{INTRODUCTION}

The idea that we should be treating cancer patients on an individual basis has become a major objective in clinical oncology (Jain, 2002). In the past 10 years, more than 200,000 articles describing biomarkers that predict treatment outcome have been published. However, few biomarkers are currently used routinely in the clinic. One very clear lesson learned is that anecdotal, underpowered biomarker studies have little clinical value and tend to significantly slow down progress. Introduction into the clinic before appropriate validation is costly and can result in the under treatment or over treatment of patients (Dammann and Weber, 2012). The translation of prospective biomarkers from the lab into validated diagnostic tests is a major challenge. This review will focus upon the discovery and development of biomarkers in glioblastoma (GBM).

\section{DEFINITION OF A BIOMARKER}

The critical hallmark of a biomarker is to be highly sensitive and specific in providing information relevant for diagnosis, prognosis, or therapy. There is no strict rule when it comes to what constitutes a biomarker. A marker can consist of alterations of the genome, epigenome, transcriptome, or proteome, aberrant microRNA as well as imaging changes observed on a MRI or PET scan. The most sought after biomarkers are the ones that can identify which patients are at high risk of tumor relapse, and cytotoxicity in response to specific chemotherapeutic agents. In addition, biomarkers that can be easily ascertained by simple and inexpensive methodologies such as immunohistochemistry (IHC) are also in demand. The use of biomarkers to identify patients who do not respond to treatment early could confer enormous benefits for patients diagnosed with GBM, especially considering their usually short survival time. A few biomarkers have shown excellent utility in survival prognostication but not necessarily at the level of influencing an oncologist's decision to administer a specific drug or alter the treatment schedule. A summary of the key biomarkers used for the diagnosis, prognosis and predicting treatment response in GBM is provided in Table $\mathbf{1}$.

\section{DIAGNOSTIC BIOMARKERS BIOMARKERS TO DISTINGUISH PRIMARY GBM FROM SECONDARY GBM}

Primary GBM develops very fast de novo, without clinical or histopathological evidence of a less malignant precursor lesion (Scherer, 1940). Secondary GBM develops from low-grade diffuse astrocytoma (LGA, WHO grade II) or anaplastic astrocytoma (AA, WHO grade III). The pace of progression to a secondary GBM varies considerably. The mean interval from LGA to secondary GBM is approximately 5 years; from AA to secondary GBM is approximately $1.5-2$ years.

From population-based clinical observations it has been estimated that approximately $5 \%$ of all GBMs are secondary. However, progression to secondary GBM may occur fast or asymptomatic and thus escape clinical detection. They constitute a distinct tumor entity with a significant difference in age distribution. Primary GBMs affect the elderly, with a mean age at diagnosis of approximately 60 years. Secondary GBM patients are approximately 15 years younger. They have a preferential location in the frontal lobe, a lower Male/Female ratio and a significantly better clinical outcome. Histopathologically, these two subtypes of GBM cannot reliably be distinguished, however their genetic profile differs significantly (Watanabe et al., 1996; Ohgaki et al., 2004).

The detection of mutations in the Krebs cycle enzyme isocitrate dehydrogenase (IDH) has become a reliable molecular test for identifying secondary GBM. Using high-throughput next generation sequencing, recurrent mutations in the active site of 
Table 1 | Biomarker summary.

\begin{tabular}{|c|c|c|c|c|c|}
\hline Biomarker & Standardized Test? & Diagnostic Use? & Prognostic Use? & Predictive Use? & Druggable Target? \\
\hline $\begin{array}{l}\text { MGMT promoter } \\
\text { methylation }\end{array}$ & $\begin{array}{l}\text { No } \\
\text { MSP, pyrosequencing, } \\
\text { RT-PCR }\end{array}$ & No & $\begin{array}{l}\text { Yes } \\
\text { Anaplastic glioma }\end{array}$ & $\begin{array}{l}\text { Yes } \\
\text { Elderly GBM }\end{array}$ & No \\
\hline IDH1/2 mutation & $\begin{array}{l}\text { Yes } \\
\text { IHC (IDH1-R132H). } \\
\text { Sequencing }\end{array}$ & $\begin{array}{l}\text { Yes } \\
\text { Can aid in the } \\
\text { differential diagnosis } \\
\text { of grade II/III glioma } \\
\text { from pilocytic } \\
\text { astrocytoma, } \\
\text { ependymomas and } \\
\text { reactive gliosis } \\
\text { Can detect the } \\
\text { infiltration of tumor } \\
\text { cells in normal tissue }\end{array}$ & $\begin{array}{l}\text { Yes } \\
\text { Prognostically } \\
\text { favourable } \\
\text { Indicative of secondary } \\
\text { GBM }\end{array}$ & No & $\begin{array}{l}\text { No } \\
\text { Mutant IDH1 is considered to } \\
\text { be a potentialtherapeutic } \\
\text { target; however no } \\
\text { treatments are available as } \\
\text { yet }\end{array}$ \\
\hline TP53mutation & $\begin{array}{l}\text { No } \\
\mathrm{IHC} \text { is commonly used } \\
\text { however this is not } \\
\text { representative of a } \\
\text { mutation }\end{array}$ & $\begin{array}{l}\text { Yes } \\
\text { Genetic hallmark in } \\
60-70 \% \text { of low-grade } \\
\text { diffuseastrocytomas, } \\
\text { anaplastic } \\
\text { astrocytomas and } \\
\text { secondary GBMs }\end{array}$ & $\begin{array}{l}\text { No } \\
\text { Some studies have } \\
\text { found a shorter time } \\
\text { interval to progression } \\
\text { in patients with TP53 } \\
\text { mutant low-grade } \\
\text { astrocytoma }\end{array}$ & No & No \\
\hline $\begin{array}{l}\text { EGFR } \\
\text { amplification }\end{array}$ & $\begin{array}{l}\text { Yes } \\
\text { IHC does not } \\
\text { differentiate between } \\
\text { EGFR amplification and } \\
\text { overexpression }\end{array}$ & $\begin{array}{l}\text { Limited } \\
\text { EGFR amplification } \\
\text { indicates primary } \\
\text { GBM }\end{array}$ & No & No & $\begin{array}{l}\text { Yes } \\
\text { Cetuximab } \\
\text { Erlotinib } \\
\text { Gefitinib } \\
\text { EGFRvIll: } \\
\text { rhindopepimut }\end{array}$ \\
\hline VEGF & $\begin{array}{l}\text { No } \\
\text { IHC, but not used } \\
\text { clinically }\end{array}$ & No & No & No & $\begin{array}{l}\text { Yes } \\
\text { bevacizumab }\end{array}$ \\
\hline
\end{tabular}

IDH1 have been identified in approximately 12\% of all GBM and were typically observed in younger patients with secondary GBM (Parsons et al., 2008). Since the IHC test for IDH mutation detection was introduced to the clinic, secondary GBMs have been shown to constitute approximately $10 \%$ of all GBMs (previously estimated at $5 \%$ on the basis of a known precursor lesion and age; Nobusawa et al., 2009). Point mutations at the arginine 132 (IDH1) and at arginine 140 or arginine 172 (IDH2) in the active site of IDH enzyme alter catalytic activity of the enzyme and results in increased production of 2-hydroxyglutarate (2-HG) which is potentially associated with increased cancer risk and glioma progression (Dang et al., 2009). A recent study showed that 2-HG also had a potential to competitively inhibit $\alpha$ ketoglutarate-dependent enzymes including histone demethylases and 5-methylcytosine hydroxylases which in turn leads to genomewide histone modifications and DNA methylation changes (Xu et al., 2011).

Additionally, mutations in the tumor suppressor TP53 are observed in 70\% of secondary GBM (Ohgaki and Kleihues, 2007). TP53 negatively regulates the proliferation of cells and plays an important role in the transcriptional activation or repression of several genes, in particular $p 21$, an inhibitor of cyclin-dependent kinases [CDKs]). Through this pathway, TP53 mediates cell cycle control at G1/S and G2/M checkpoints (Agarwal et al., 1995). Many laboratories use IHC to detect TP53 expression, but in CNS tumors, immunoreactivity is not representative of the gene mutation status.

\section{PROGNOSTIC BIOMARKERS \\ CLASSICAL PHENOTYPICAL TRAITS}

By definition, a prognostic marker has the capacity to estimate survival outcome, independent of whether or not the patient receives adjuvant radiation therapy (RT) and/or chemotherapy. Classical phenotypical traits that are prognostic for survival include age, performance status, tumor location, and histological grade. Older age has been consistently associated with poor prognosis. In a historical population-based study, there was a linear decrease of overall survival with increasing age. Patients aged 70-79 years had a median survival of 2.9 months, those above 80 years only 1.9 months (Ohgaki et al., 2004). Similarly, a high preoperative performance status has a favorable prognostic impact, irrespective of subsequent adjuvant therapy (Lacroix et al., 2001; Whittle et al., 
2002; Buckner, 2003). Size and location are also highly prognostic, with the worst outcome for GBMs being tumors that have spread extensively, e.g., across the corpus callosum to the contralateral hemisphere (Buckner, 2003).

\section{USING GENOMIC CHANGES IN GBM AS A DIAGNOSTIC TOOL TO SELECT PATIENTS FOR TARGETED THERAPY}

GBM is highly heterogeneous. The 2007 World Health Organization (WHO) classification of tumors lists giant cell GBM and gliosarcoma as histological variants of GBM. These rare subtypes reflect the marked genomic instability of the tumors. However the variable survival times of patients suggests that there are multiple subtypes of GBM. The genetic profiling of large tumor cohorts with comprehensive clinical and survival data has promoted the discovery of novel molecular biomarkers associated with survival, in addition to traditional clinical and morphological features (Nutt et al., 2003; Rich et al., 2005; Colman et al., 2010; Verhaak et al., 2010). In GBM, comprehensive gene sequencing performed by The Cancer Genome Atlas (TCGA) has identified an average of 47 mutations per tumor, although far fewer were candidates to be driver mutations (Parsons et al., 2008). Driver mutations were most frequent in the TP53, RB1, and PI3K/PTEN pathways. Mutations in these pathways were generally mutually exclusive, suggesting that they are key to tumorigenesis, and functionally equivalent (Parsons et al., 2008).

At least two distinct cluster profiles have been identified: proneural and mesenchymal-angiogenic signatures, which differ in survival and response to treatment (Colman et al., 2010; Verhaak et al., 2010). Verhaak et al. (2010) performed consensus clustering on the results of TCGA gene expression arrays from 200 samples of GBM, proposing classification into not two, but four subtypes: proneural, neural, classical, and mesenchymal. Younger age and longer survival were common features of patients with proneural subtypes. Patients benefiting from concurrent chemotherapy were associated with the classical GBM subtype. The mesenchymal GBM subgroup was connected with poor survivorship. Similar frequently mutated genes were identified to previous work, including TP53, PTEN, NF1, EGFR, IDH1, PIK3R1, RB1, ERBB2, EGFRvIII, PIK3CA, and PDGFRA. They identified clinical correlations, for example with younger age and proneural subtype, as well as survival differences by treatment, such as benefits from combined chemoradiotherapy in the classical subtype which were not seen in the proneural subtype. Secondary GBMs with IDH1/2 mutations have almost always a proneural signature.

Unfortunately no single classification is yet regarded as definitive, and our use of technology and understanding of what is clinically translatable continues to evolve (Vitucci et al., 2011). A comprehensive study of microarray data from four different independent data sets by Colman et al. (2010) identified a 38-gene signature associated with survival (31 genes associated with poor survival outcome). A smaller 9-gene signature based upon the 38 genes was tested on FFPE tissue from patients enrolled in the RTOG 0825 Phase III trial of newly diagnosed GBM.

There is a lack of confidence from biologists and diagnostic laboratories to use the 9-gene signature and/or to group GBM according to subtypes because the literature keeps changing. In a more recent study by Shen et al. (2012), three distinct GBM subtypes were identified using integrative subtype analysis of TCGA GBM dataset. There were overlaps between the Verhaak and Coleman studies but there were also striking differences. However, there is consensus in the neuro-oncology community to subtype GBM, even if it is into the broader groups of proneural and mesenchymal or suptype 1 and 3. Clinical trial efficacy with preselected patient populations will improve. It is anticipated that the IDH1/2 mutational status will prove to be most reliable and significant.

\section{GENOTYPE-DIRECTED THERAPY (DRUGGABLE BIOMARKERS) \\ EPIDERMAL GROWTH FACTOR RECEPTOR}

Tumors belonging to the subtype 2 described by Shen and colleagues or the "classical" subtype coined by Verhaak and colleagues are associated with Epidermal growth factor receptor (EGFR) copy number amplification. This is the most common EGFR alteration found in $30-50 \%$ of GBM patients, leading to increased EGFR expression, activity of the EGF pathway, cell growth, and proliferation (Shinojima et al., 2003). EGFR amplified tumors can also harbor mutations, with the most common being an in-frame deletion of exons 2-7 (known as EGFR vIII; Pelloski et al., 2007). This deletion is present in 50-60\% of GBM patients with EGFR amplification (Del Vecchio et al., 2012). EGFR overexpression detected by IHC is not representative of EGFR amplification, yet this test is commonly used.

Because of the frequency of EGFR aberrations, it is not surprising that there have been concerted efforts to therapeutically target EGFR. Inhibitors have been approved for use in non-small cell lung cancer (NSCL) and have gone to clinical trial in GBM; however the results have been very disappointing. Many patients with GBM either do not respond to these inhibitors from the outset and those patients that do respond, end up developing resistance. Cetuximab (Erbitux) has been shown to act synergistically in combination with cytostatic drugs and radiotherapy. More recently it has been shown that GBMs carrying a novel exon 27 deletion mutation (EGFR-CTD) respond better to cetuximab (Cho et al., 2011). Small molecule tyrosine kinase inhibitors (TKIs) including erlotinib (Tarceva ${ }^{\circledR}$ ) and gefitinib (Iressa ${ }^{\circledR}$ ) have also been investigated in GBM trials with disappointing outcomes. Recently these poor results have been attributed to the different conformational requirements of mutant EGFR in NSCL and GBM (Vivanco et al., 2012). EGFR inhibitors that target the active kinase conformation such as erlotinib are ineffective as a result of mutations or deletions in the extracellular domain resulting in EGFR addiction (Vivanco et al., 2012). NSCL susceptible to EGFR treatment tend to harbor mutations in the EGFR kinase domain.

The PTEN tumor suppressor gene also plays a key role in resistance to EGFR inhibitors. Loss or mutation of this gene occurs in $\sim 40 \%$ of GBM. Functional PTEN (retention of activity) has been linked to favorable response to erlotinib (Mellinghoff et al., 2005) however this could not be confirmed clinically (van den Bent et al., 2009). Additionally, phosphorylation of the conserved residue of Y240 in GBM has been shown to be associated with resistance to EGFR therapy (Fenton et al., 2012). 


\section{VASCULAR ENDOTHELIAL GROWTH FACTOR}

Vascular Endothelial Growth Factor (VEGF) is highly expressed in GBM and is a critical component of the pathophysiology (Folkman, 1995; Jain et al., 2007) and numerous experimental studies have supported a major role for VEGF in tumor angiogenesis (Dowlati and $\mathrm{Fu}, 2008$ ) B Blocking VEGF leads to impeded vessel growth and endothelial cell proliferation, vasoconstriction and vessel "normalization" which results in redistribution of blood flow in tumor tissue and improves delivery of anti-cancer agents to individual cells (McVicker and Tabatabai, 2006; Weiner et al., 2006). Bevacizumab targets VEGF-2, while the drugs cediranib (Wachsberger et al., 2011) and sunitinib (D'Amico et al., 2012) target also VEGFR-1, -2, and -3. The efficacy of cediranib was trialed in a Phase III study of recurrent GBM patients as a monotherapy and in combination with lomustine versus lomustine alone (REGAL study). Although there was evidence of activity, cediranib treatment did not improve survival (Ahluwalia, 2011).

The use of bevacizumab as a second line treatment for GBM was fast-tracked in the USA 3 years ago (Cohen et al., 2009; Cloughesy, 2010). FDA approval was based on positive results from two prospective phase II trials on patients with relapsed tumors (Vredenburgh et al., 2007; Friedman et al., 2009). Although close to half of patients treated with bevacizumab show a dramatic radiological response rate and an increased median progression free survival (PFS) compared to historic controls, no impact on overall survival has been reported (Friedman et al., 2009; Chamberlain, 2011).

\section{SUMMARY OF THE CURRENT STATE OF GENOTYPE-DIRECTED THERAPY}

There is no doubt that genotype-directed medicine holds great promise for the treatment of tumors. However, we recognize that a multi-facetted, combination therapy approach will be necessary. In addition, what works in one cancer such as the EGFR inhibitors in NSCLC may not be effective in another solid cancer harboring the same mutation as a result of conformational changes. Additionally, there strong cross talk between the signaling pathways significantly adds to the complexities of genotype-targeted treatment of a tumor. Subtyping of GBM prior to clinical trial is essential. Clinical and research laboratories need to agree on a minimal molecular testing platform, whether it be the gene signatures or the testing of individual molecular markers and agreement on the methodologies must come into play.

\section{BIOMARKERS WITH TREATMENT PREDICTIVE VALUE}

Much more difficult to identify are biomarkers with predictive power in the context of a specific therapy. Predictive biomarkers are markers that can be used to identify groups of patients who are most likely to respond to a given treatment. The key difference between a prognostic and a predictive biomarker is that a predictive biomarker should instigate a change in the treatment provided to the patient.

\section{$0^{6}$-METHYLGUANINE-DNA METHYLTRANSFERASE: IS METHYLATION OF MGMT PREDICTIVE OF RESPONSE TO TEMOZOLOMIDE?}

Detection of methylation within the promoter region of $O^{6}$ methylguanine-DNA methyltransferase (MGMT) gene has clearly provided the most meaningful clinical correlation and is generally accepted as a predictive and prognostic biomarker in temozolomide treated GBM, even in elderly patients (Stupp et al., 2005a, 2009; Reifenberger et al., 2012; Wick et al., 2012). The MGMT gene is located on chromosome 10q26.1 and encodes a DNA repair protein that restores mutagenic $\mathrm{O}^{6}$-alkylguanine to normal guanine within genomic DNA. Alkylating drugs such as temozolomide are used in chemotherapy for the targeted cell death of rapidly replicating neoplastic cells and MGMT expression is a key factor in conferring resistance to these agents. Loss of MGMT protein expression is frequently associated with transcriptional silencing of the MGMT gene by methylation of its $\mathrm{CpG}$ island promoter in various neoplasia, (Esteller et al., 1999) as exemplified by $35-55 \%$ of gliomas (Silber et al., 1999; Esteller et al., 2001; Nakamura et al., 2001; Kamiryo et al., 2004; Brell et al., 2005; Hegi et al., 2005).

There has been considerable and long-held enthusiasm to use MGMT as a predictive biomarker for glioma patients, with the longer term hope for its use as a marker to assign therapy to individual patients. Three criteria for predictive biomarkers were recently developed by the Evaluation of Genomic Applications in Practice and Prevention (EGAPP) Working Group convened by the Centers for Disease Control: (1) Analytical validity; (2) Clinical Validity; and (3) Clinical Utility. We herein apply these paradigms to MGMT as a predictive biomarker.

\section{Analytical validity}

Pre-analytical and analytical factors that contribute to accuracy, reliability and reproducibility of the specific assay test for MGMT promoter methylation testing has become a controversial issue. There is still no consensus on the optimal method to be applied. Assessment of MGMT promoter methylation is difficult due to the complex nature of the techniques involved. To detect methylation, bisulfite treatment of the DNA is required, a process that may result in degradation of DNA and subsequent low success rates in PCR. This is further compounded by the fact that the most commonly available tissue for assessment is FFPE, and the DNA subsequently extracted is typically fragmented, again making PCR more difficult. Promoter methylation analysis by qualitative methyl-specific polymerase chain reaction (MSP) or semi-quantitative methyl-specific polymerase chain reaction (SQMSP), especially from FPPE tissue is technically demanding. MSP is the more limited because the methylation status of only a few $\mathrm{CpG}$ sites (i.e., those interfering with the PCR primer binding) can be interrogated at once. The technique also has the drawback of providing only a qualitative indication of the methylation status of the sites. Karayan-Tapon et al. (2010) evaluated MGMT promoter methylation using MSP, SQ-MSP, and pyrosequencing. The best predictive value for overall survival was obtained by pyrosequencing which is a technique that generates a quantitative measure of methylation and automatically calculates and reports percent methylation for each $\mathrm{CpG}$ site in the studied sequence, thus allowing detection of partially methylated $\mathrm{CpG}$ sites. The problem with pyrosequencing, however, is the different $\%$ cut-offs for methylation and clinical relevance of the cut-off chosen. Two regions tightly associated with patient survival were recently identified by Bady et al. (2012) using an Infinium methylation BeadChip. The latter of the two regions is within the $59 \mathrm{bp}$ enhancer region, 
between the exon 1 and intron boundary of the MGMT gene. The majority of PCR assays, including the MSP and pyrosequencing, target this region.

\section{Clinical validity}

O6-methylguanine-DNA methyltransferase promoter methylation status is clinically well founded. In 2005, in a companion study conducted on tumor specimens from patients enrolled in the EORTC_26981/NCIC_CE.3 (Stupp et al., 2005b), Hegi et al. (2005) demonstrated a pronounced favorable response in patients whose tumors had lost MGMT activity via promoter methylation. The median survival for patients with methylated MGMT was 21.7 months compared to 12.7 months for patients with unmethylated MGMT. MGMT status can reliably distinguish two or more subgroups within a population that have different biological and clinical outcomes and has been used to stratify patient populations in a number of Phase II trials (Grossman et al., 2009; Fabi et al., 2010; Peereboom et al., 2010; Weiler et al., 2010; Lai et al., 2011). The strong prognostic role for MGMT promoter methylation in GBM treated with concurrent RT and TMZ was prospectively confirmed by the Radiation Therapy Oncology Group (RTOG) study 0525 (Ahluwalia, 2011).

The testing of patients for MGMT promoter methylation has been incorporated in numerous trials. A better response to cilengitide treatment in a phase I/IIa trial was observed in MGMT methylated patients (Stupp et al., 2010). In response, recruitment to the Phase III trial; Cilengitide, Temozolomide, and RT in Treating Patients With Newly Diagnosed GBM and Methylated Gene Promoter Status [CENTRIC]; NCT00689221 was restricted to patients with MGMT promoter methylation. The outcome of this trial is not yet known. The RTOG 0825 trial (mentioned earlier), examining the effect of bevacizumab administered with radiotherapy compared to conventional concurrent chemoradiotherapy (TMZ) in primary GBM also incorporated MGMT promoter methylation testing for all patients (Colman et al., 2010).

Two studies exploring the different treatment regimes in the elderly (patients aged over 60 years and diagnosed with a GBM): the German Neuro-oncology Group trial, NOA-08 (Wick et al., 2012) and the Nordic study (Malmstrom et al., 2012), also showed that MGMT promoter methylation was both prognostic and predictive for response to alkylating therapy. In both studies, survival was significantly improved in the MGMT methylated patients when treated with temozolomide, thus establishing MGMT as a predictive biomarker in this patient population. In contrast, MGMT promoter methylation appears to have no predictive capacity in anaplastic glioma. The NOA-04 trial showed a striking difference in PFS between patients with versus without MGMT promoter methylation who were treated with radiotherapy alone (Wick et al., 2012).

\section{Clinical Utility}

Clinical validity does not imply that a tumor biomarker assay should be used to care for patients. Prospective testing of elderly GBM patients for MGMT to determine if they should receive temozolomide is a significant advancement in clinical treatment. If MGMT methylated, up front temozolomide will be offered to this patient group. Importantly, these patients will be spared the radiotherapy which may lead to significant deficits including tiredness and memory loss. MGMT promoter methylation can also help to distinguish true tumor progression from pseudoprogression. Park et al. (2011) combined MS-MLPA and MSP methodologies for detecting MGMT methylation of which resulted in a diagnostic accuracy of $93 \%$ for the identification of pseudoprogression as opposed to radiological progression in GBM patients. It is critical to distinguish pseudoprogression because misinterpretation can lead to early treatment cessation or surgery.

The usefulness of testing for MGMT promoter methylation in all GBM patients in a routine clinical setting will come to fruition when an alternative treatment strategy is available. Until then, it is difficult and highly contentious for clinicians to base their decisions on whether or not they should withhold temozolomide treatment in patients with unmethylated MGMT and a good performance status.

With this recognition that an unmethylated MGMT promoter is associated with a poorer response to temozolomide, strategies have evolved to circumvent the resistance that MGMT confers. Numerous studies, including the multicenter RTOG 0525 have examined altered TMZ dosing regimes, but no significant survival benefits have been conferred (Brock et al., 1998; Wick et al., 2007, 2009; Perry et al., 2008; Ahluwalia, 2011). The MGMT unmethylated population of patients needs to be put on center stage for new treatment strategies.

\section{THE FUTURE OF BIOMARKER DISCOVERY AND IMPLEMENTATION INTO THE CLINIC}

We need to review where we are going wrong with biomarker discovery and development and identify the steps required to improve their clinical value and utility. First and foremost, we need to be asking the right questions. Is this biomarker involved in driving the cancer growth? Is this biomarker druggable? And of upmost importance, is it clinically relevant? Will this biomarker lead to a clinician altering their clinical decision? The collection of quality preserved tumor tissue that has undergone independent histological review will improve biomarker discovery. In the cases where biomarkers have been identified, standardized testing needs to be implemented.

\section{IMPORTANCE OF HIGH QUALITY TUMOR BANKING}

The majority of biomarkers stem from studies on tumor tissue. Less than perfect tissue will lead to false-positives. Substandard tissue and data collection provided a significant obstacle to the TCGA effort. Standard operating procedures (SOPs) are not consistent between sites, and sometimes differ within single institutions. Methodologies for preserving tissue vary and times between tumor removal and time of processing fluctuate. Significant changes can occur between the time interval between tissue removal and processing. Despite this knowledge, in many centers, biorepositories remain underfunded. The collection of tissue needs to be taken seriously and investments are essential to promote basic, translational, and clinical research as well as social gain in terms of improved cancer care and economic development. 
The same standards should apply to FFPE. However, unlike for frozen tissue, the time intervals taken for preservation are usually not recorded. Enrollment onto clinical trials is now often dependent upon receipt of FFPE tissue for central pathology and additional molecular tests such as Ion Torrent PMG sequencing which is a tailored platform to cater for FFPE tissue. Experience at one site in Australia revealed that FFPE specimens from patients operated between Monday-Thursday typically passed quality control and DNA extracted from these tissues tended to be suitable for sequencing. However, there were a sizeable number of FFPE samples that did not make the grade. These samples were usually from patients who were operated on a Thursday evening or a Friday. An investigation of the problem revealed that the specimens were kept in formalin solution for up to $72 \mathrm{~h}$ because samples were not processed over the weekend.

\section{HISTOLOGICAL REVIEW}

Histological classification of gliomas shows a significant interobserver variability, particular in the distinction of astrocytomas vs. oligodendrogliomas and oligoastrocytomas (Kim et al., 2010). Similarly, the diagnosis of anaplastic astrocytoma can be very challenging (van den Bent, 2010). GBMs can easily be classified as anaplastic astrocytoma if the histological hallmarks necrosis and/or microvascular proliferation are not detected due to a sampling error. There is a need that all glioma diagnoses be complemented by a minimum set of genetic characteristic, including IDH1 and TP53 mutation, 1p/19q co-deletion, and EGFR amplification.

\section{STANDARDIZATION OF METHODOLOGY FOR BIOMARKER TESTING}

There is also an apparent lack of standardization in the methods used for biomarker measurement. Assays for biomarkers need to

\section{REFERENCES}

Agarwal, M. L., Agarwal, A., Taylor, W. R., and Stark, G. R. (1995). p53 controls both the G2/M and the G1 cell cycle checkpoints and mediates reversible growth arrest in human fibroblasts. Proc. Natl. Acad. Sci. U.S.A. 92, 8493-8497.

Ahluwalia, M. S. (2011). 2010 Society for neuro-oncology annual meeting: a report of selected studies. Expert Rev. Anticancer Ther. 11, 161-163.

Bady, P., Sciuscio, D., Diserens, A. C., Bloch, J., Van Den Bent, M. J., Marosi, C., et al. (2012). MGMT methylation analysis of glioblastoma on the Infinium methylation BeadChip identifies two distinct CpG regions associated with gene silencing and outcome, yielding a prediction model for comparisons across datasets, tumor grades, and CIMP-status. Acta Neuropathol. 124, 547-560.

Brell, M., Tortosa, A., Verger, E., Gil, J. M., Vinolas, N., Villa, S., et al. (2005). Prognostic significance

be reliable. The assay needs to give identical results if repeated in the same or in another laboratory. The result needs to be the same, even when different methodologies are used. And finally, we need to ask whether the test provides added value to clinical practice. TCGA analyses have identified a high diversity of genes mutated within GBM. As prices drop with Next Generation sequencing, capabilities to better define genetic aberrations associated with response to a specific treatment will improve. Copy number aberrations (amplifications and deletions) and structural aberrations (intra-chromosomal rearrangements-inversions, inverted/tandem duplications) are not detected using traditional Sanger sequencing. Our ability to assess these aberrations must improve at the rate that targeted therapies emerge.

\section{CONCLUSION}

To advance personalized medicine, a co-operative effort between cancer researchers and clinicians is needed. There is also insufficient collaboration within various scientific teams working on targeted therapies such as the TKIs and anti-angiogenics. Specific consideration needs to be paid to increasing sample sizes, sequencing entire genes, implementing robust methodologies and taking a holistic approach to understanding pathways. Cancer is multifaceted and it is our task to unravel these complexities. With highly integrated teams of multidisciplinary investigators, a better overall survival of GBM patients is achievable.

\section{ACKNOWLEDGMENTS}

The authors would like to gratefully acknowledge the financial support from the Cure For Life Foundation. Dr Kerrie McDonald is a recipient of the Cancer Institute of NSW Career Development Fellowship and Dr. Paul Kleihues is the recipient of the inaugural Cure For Life Foundation Visting Professorship.

Cloughesy, T. (2010). FDA accelerated approval benefits glioblastoma. Lancet Oncol. 11, 1120.

Cohen, M. H., Shen, Y. L., Keegan, P., and Pazdur, R. (2009). FDA drug approval summary: bevacizumab (Avastin) as treatment of recurrent glioblastoma multiforme. Oncologist 14, 1131-1138.

Colman, H., Zhang, L., Sulman, E. P., McDonald, J. M., Shooshtari, N. L., Rivera, A., et al. (2010). A multigene predictor of outcome in glioblastoma. Neuro-oncology 12, 49-57.

D’Amico, R., Lei, L., Kennedy, B. C., Sisti, J., Ebiana, V., Crisman, C., et al. (2012). The addition of Sunitinib to radiation delays tumor growth in a murine model of glioblastoma. Neurol. Res. 34, 252-261.

Dammann, M., and Weber, F. (2012). Personalized medicine: caught between hope, hype and the real world. Clinics (Sao Paulo) 67(Suppl 1), 91-97.

Dang, L., White, D. W., Gross, S., Bennett, B. D., Bittinger, M. A.,
Driggers, E. M., et al. (2009). Cancer-associated IDH1 mutations produce 2-hydroxyglutarate. Nature 462, 739-744.

Del Vecchio, C. A., Giacomini, C. P., Vogel, H., Jensen, K. C., Florio, T., Merlo, A., et al. (2012). EGFRvIII gene rearrangement is an early event in glioblastoma tumorigenesis and expression defines a hierarchy modulated by epigenetic mechanisms. Oncogene. doi: 10.1038/onc.2012.280. [Epub ahead of print].

Dowlati, A., and Fu, P. (2008). Is response rate relevant to the phase II trial design of targeted agents? J. Clin. Oncol. 26, 1204-1205.

Esteller, M., Hamilton, S. R., Burger, P. C., Baylin, S. B., and Herman, J. G. (1999). Inactivation of the DNA repair gene O6methylguanine-DNA methyltransferase by promoter hypermethylation is a common event in primary human neoplasia. Cancer Res. 59, 793-797. 
Esteller, M., Risques, R. A., Toyota, M., Capella, G., Moreno, V., Peinado, M. A., et al. (2001). Promoter hypermethylation of the DNA repair gene $\mathrm{O}(6)$-methylguanine-DNA methyltransferase is associated with the presence of $\mathrm{G}: \mathrm{C}$ to $\mathrm{A}: \mathrm{T}$ transition mutations in $\mathrm{p} 53$ in human colorectal tumorigenesis. Cancer Res. 61, 4689-4692.

Fabi, A., Metro, G., Vidiri, A., Lanzetta, G., Carosi, M., Telera, S., et al. (2010). Low-dose fotemustine for recurrent malignant glioma: a multicenter phase II study. J. Neurooncol. 100, 209-215.

Fenton, T. R., Nathanson, D., Ponte De Albuquerque, C., Kuga, D., Iwanami, A., Dang, J., et al. (2012). Resistance to EGF receptor inhibitors in glioblastoma mediated by phosphorylation of the PTEN tumor suppressor at tyrosine 240 . Proc. Natl. Acad. Sci. U.S.A. 109, 14164-14169.

Folkman, J. (1995). Angiogenesis in cancer, vascular, rheumatoid and other disease. Nat. Med. 1, 27-31.

Friedman, H. S., Prados, M. D., Wen, P. Y., Mikkelsen, T., Schiff, D., Abrey, L. E., et al. (2009). Bevacizumab alone and in combination with irinotecan in recurrent glioblastoma. J. Clin. Oncol. 27, 4733-4740.

Grossman, S. A., Ye, X., Chamberlain, M., Mikkelsen, T., Batchelor, T., Desideri, S., et al. (2009). Talampanel with standard radiation and temozolomide in patients with newly diagnosed glioblastoma: a multicenter phase II trial. J. Clin. Oncol. 27, 4155-4161.

Hegi, M. E., Diserens, A. C., Gorlia, T., Hamou, M. F., De Tribolet, N., Weller, M., et al. (2005). MGMT gene silencing and benefit from temozolomide in glioblastoma. N. Engl. J. Med. 352, 997-1003.

Jain, K. K. (2002). Personalized medicine. Curr. Opin. Mol. Ther. 4, 548-558.

Jain, R. K., Di Tomaso, E., Duda, D. G., Loeffler, J. S., Sorensen, A. G., and Batchelor, T. T. (2007). Angiogenesis in brain tumours. Nat. Rev. Neurosci. $8,610-622$.

Kamiryo, T., Tada, K., Shiraishi, S., Shinojima, N., Kochi, M., and Ushio, Y. (2004). Correlation between promoter hypermethylation of the O6methylguanine-deoxyribonucleic acid methyltransferase gene and prognosis in patients with highgrade astrocytic tumors treated with surgery, radiotherapy, and 1-(4-amino-2-methyl5-pyrimidinyl)methyl-3-(2-

chloroethyl)-3-nitrosourea-based chemotherapy. Neurosurgery 54, 349-357 [discussion 357].

Karayan-Tapon, L., Quillien, V., Guilhot, J., Wager, M., Fromont, G., Saikali, S., et al. (2010). Prognostic value of O6-methylguanine-DNA methyltransferase status in glioblastoma patients, assessed by five different methods. J. Neurooncol. 97, 311-322.

Kim, Y. H., Nobusawa, S., Mittelbronn, M., Paulus, W., Brokinkel, B., Keyvani, K., et al. (2010). Molecular classification of low-grade diffuse gliomas. Am. J. Pathol. 177, 2708-2714.

Lacroix, M., Abi-Said, D., Fourney, D. R., Gokaslan, Z. L., Shi, W., Demonte, F., et al. (2001). A multivariate analysis of 416 patients with glioblastoma multiforme: prognosis, extent of resection, and survival. J. Neurosurg. 95, 190-198.

Lai, A., Tran, A., Nghiemphu, P. L., Pope, W. B., Solis, O. E., Selch, M., et al. (2011). Phase II study of bevacizumab plus temozolomide during and after radiation therapy for patients with newly diagnosed glioblastoma multiforme. J. Clin. Oncol. 29, 142-148.

Malmstrom, A., Gronberg, B. H., Marosi, C., Stupp, R., Frappaz, D., Schultz, H., et al. (2012). Temozolomide versus standard 6week radiotherapy versus hypofractionated radiotherapy in patients older than 60 years with glioblastoma: the Nordic randomised, phase 3 trial. Lancet Oncol. 13, 916-926.

McVicker, J. K., and Tabatabai, L. B. (2006). Isolation and characterization of the P5 adhesin protein of Haemophilus parasuis serotype 5. Prep. Biochem. Biotechnol. 36, 363-374.

Mellinghoff, I. K., Wang, M. Y., Vivanco, I., Haas-Kogan, D. A., Zhu, S., Dia, E. Q., et al. (2005). Molecular determinants of the response of glioblastomas to EGFR kinase inhibitors. $N$. Engl. J. Med. 353, 2012-2024.

Nakamura, M., Watanabe, T., Yonekawa, Y., Kleihues, P., and Ohgaki, H. (2001). Promoter methylation of the DNA repair gene MGMT in astrocytomas is frequently associated with $\mathrm{G}: \mathrm{C} \rightarrow \mathrm{A}: \mathrm{T}$ mutations of the TP53 tumor suppressor gene. Carcinogenesis 22, 1715-1719.

Nobusawa, S., Watanabe, T., Kleihues, P., and Ohgaki, H. (2009). IDH1 mutations as molecular signature and predictive factor of secondary glioblastomas. Clin. Cancer Res. 15, 6002-6007.

Nutt, C. L., Mani, D. R., Betensky, R. A., Tamayo, P., Cairncross, J. G., Ladd, C., et al. (2003). Gene expressionbased classification of malignant gliomas correlates better with survival than histological classification. Cancer Res. 63, 1602-1607.

Ohgaki, H., Dessen, P., Jourde, B., Horstmann, S., Nishikawa, T., Di Patre, P. L., et al. (2004). Genetic pathways to glioblastoma: a population-based study. Cancer Res. 64, 6892-6899.

Ohgaki, H., and Kleihues, P. (2007). Genetic pathways to primary and secondary glioblastoma. Am. J. Pathol. 170, 1445-1453.

Park, C. K., Kim, J., Yim, S. Y., Lee, A. R., Han, J. H., Kim, C. Y., et al. (2011). Usefulness of MS-MLPA for detection of MGMT promoter methylation in the evaluation of pseudoprogression in glioblastoma patients. Neuro-oncology 13, 195-202.

Parsons, D. W., Jones, S., Zhang, X., Lin, J. C., Leary, R. J., Angenendt, P., et al. (2008). An integrated genomic analysis of human glioblastoma multiforme. Science 321, 1807-1812.

Peereboom, D. M., Shepard, D. R., Ahluwalia, M. S., Brewer, C. J., Agarwal, N., Stevens, G. H., et al. (2010). Phase II trial of erlotinib with temozolomide and radiation in patients with newly diagnosed glioblastoma multiforme. J. Neurooncol. 98, 93-99.

Pelloski, C. E., Ballman, K. V., Furth, A. F., Zhang, L., Lin, E., Sulman, E. P., et al. (2007). Epidermal growth factor receptor variant III status defines clinically distinct subtypes of glioblastoma. J. Clin. Oncol. 25, 2288-2294.

Perry, J. R., Rizek, P., Cashman, R., Morrison, M., and Morrison, T. (2008). Temozolomide rechallenge in recurrent malignant glioma by using a continuous temozolomide schedule: the "rescue" approach. Cancer 113 2152-2157.

Reifenberger, G., Hentschel, B., Felsberg, J., Schackert, G., Simon, M., Schnell, O., et al. (2012). Predictive impact of MGMT promoter methylation in glioblastoma of the elderly. Int. J. Cancer 131, 1342-1350.

Rich, J. N., Hans, C., Jones, B., Iversen, E. S., McLendon, R. E., Rasheed, B. K., et al. (2005). Gene expression profiling and genetic markers in glioblastoma survival. Cancer Res. 65, 4051-4058.

Scherer, H. J. (1940). A critical review: the pathology of cerebral gliomas. $J$. Neurol. Psychiatry 3, 147-177.
Shen, R., Mo, Q., Schultz, N., Seshan, V. E., Olshen, A. B., Huse, J., et al. (2012). Integrative subtype discovery in glioblastoma using iCluster. PLoS ONE 7:e35236. doi:10.1371/journal.pone.0035236

Shinojima, N., Tada, K., Shiraishi, S., Kamiryo, T., Kochi, M., Nakamura H., et al. (2003). Prognostic value of epidermal growth factor receptor in patients with glioblastoma multiforme. Cancer Res. 63, 6962-6970.

Silber, J. R., Blank, A., Bobola, M. S., Ghatan, S., Kolstoe, D. D., and Berger, M. S. (1999). O6-methylguanine-DNA methyltransferase-deficient phenotype in human gliomas: frequency and time to tumor progression after alkylating agent-based chemotherapy. Clin. Cancer Res. 5, 807-814.

Stupp, R., Hegi, M. E., Mason, W. P., Van Den Bent, M. J., Taphoorn, M. J., Janzer, R. C., et al. (2009). Effects of radiotherapy with concomitant and adjuvant temozolomide versus radiotherapy alone on survival in glioblastoma in a randomised phase III study: 5-year analysis of the EORTC-NCIC trial. Lancet Oncol. 10, 459-466.

Stupp, R., Hegi, M. E., Neyns, B., Goldbrunner, R., Schlegel, U., Clement, P. M., et al. (2010). Phase I/IIa study of cilengitide and temozolomide with concomitant radiotherapy followed by cilengitide and temozolomide maintenance therapy in patients with newly diagnosed glioblastoma. J. Clin. Oncol. 28, 2712-2718.

Stupp, R., Mason, W. P., Van Den Bent, M. J., Weller, M., Fisher, B., Taphoorn, M. J., et al. (2005a), Radiotherapy plus concomitant and adjuvant temozolomide for glioblastoma. N. Engl. J. Med. 352, 987-996.

Stupp, R., Van Den Bent, M. J., and Hegi, M. E. (2005b). Optimal role of temozolomide in the treatment of malignant gliomas. Curr. Neurol. Neurosci. Rep. 5, 198-206.

van den Bent, M. J. (2010). Interobserver variation of the histopathological diagnosis in clinical trials on glioma: a clinician's perspective. Acta Neuropathol. 120, 297-304.

van den Bent, M. J., Brandes, A. A., Rampling, R., Kouwenhoven, M. C., Kros, J. M., Carpentier, A. F., et al. (2009). Randomized phase II trial of erlotinib versus temozolomide or carmustine in recurrent glioblastoma: EORTC brain tumor group study 26034 . J. Clin. Oncol. 27, 1268-1274.

Verhaak, R. G., Hoadley, K. A., Purdom, E., Wang, V., Qi, Y., Wilkerson, M. 
D., et al. (2010). Integrated genomic analysis identifies clinically relevant subtypes of glioblastoma characterized by abnormalities in PDGFRA, IDH1, EGFR, and NF1. Cancer Cell 17, 98-110.

Vitucci, M., Hayes, D. N., and Miller, C. R. (2011). Gene expression profiling of gliomas: merging genomic and histopathological classification for personalised therapy. Br. J. Cancer 104, 545-553.

Vivanco, I., Robins, H. I., Rohle, D., Campos, C., Grommes, C., Nghiemphu, P. L., et al. (2012). Differential sensitivity of glioma- versus lung cancer-specific EGFR mutations to EGFR kinase inhibitors. Cancer Discov. 2, 458-471.

Vredenburgh, J. J., Desjardins, A., Herndon, J. E. II, Marcello, J., Reardon, D. A., Quinn, J. A., et al. (2007). Bevacizumab plus irinotecan in recurrent glioblastoma multiforme. J. Clin. Oncol. 25, 4722-4729.

Wachsberger, P. R., Lawrence, R. Y., Liu, Y., Xia, X., Andersen, B., and Dicker, A. P. (2011). Cediranib enhances control of wild type EGFR and EGFRvIII-expressing gliomas through potentiating temozolomide, but not through radiosensitization: implications for the clinic. J. Neurooncol. 105, 181-190.

Watanabe, K., Tachibana, O., Sata, K., Yonekawa, Y., Kleihues, P., and Ohgaki, H. (1996). Overexpression of the EGF receptor and p53 mutations are mutually exclusive in the evolution of primary and secondary glioblastomas. Brain Pathol. 6, 217-223 [discussion 223-214].

Weiler, M., Hartmann, C., Wiewrodt, D., Herrlinger, U., Gorlia, T., Bahr, O., et al. (2010). Chemoradiotherapy of newly diagnosed glioblastoma with intensified temozolomide. Int J. Radiat. Oncol. Biol. Phys. 77, 670-676.

Weiner, D. E., Tabatabai, S., Tighiouart, H., Elsayed, E., Bansal, N., Griffith, J., et al. (2006). Cardiovascular outcomes and all-cause mortality: exploring the interaction between CKD and cardiovascular disease. Am. J. Kidney Dis. 48, 392-401.

Whittle, I. R., Basu, N., Grant, R., Walker, M., and Gregor, A. (2002). Management of patients aged $>60$ years with malignant glioma: good clinical status and radiotherapy determine outcome. Br. J. Neurosurg. 16 343-347.

Wick, A., Felsberg, J., Steinbach, J. P., Herrlinger, U., Platten, M., Blaschke, B., et al. (2007). Efficacy and tolerability of temozolomide in an alternating weekly regimen in patients with recurrent glioma. J. Clin. Oncol. 25, 3357-3361.

Wick, W., Platten, M., Meisner, C. Felsberg, J., Tabatabai, G., Simon, M., et al. (2012). Temozolomide chemotherapy alone versus radiotherapy alone for malignant astrocytoma in the elderly: the NOA-08 randomised, phase 3 trial. Lancet Oncol. 13, 707-715.

Wick, W., Platten, M., and Weller, M. (2009). New (alternative) temozolomide regimens for the treatment of glioma. Neuro-oncology 11 , 69-79.

Xu, W., Yang, H., Liu, Y., Yang, Y. Wang, P., Kim, S. H., et al. (2011). Oncometabolite 2-hydroxyglutarate is a competitive inhibitor of alpha-ketoglutarate-dependent dioxygenases. Cancer Cell 19, 17-30.
Conflict of Interest Statement: The authors declare that the research was conducted in the absence of any commercial or financial relationships that could be construed as a potential conflict of interest.

Received: 13 October 2012; accepted: 22 December 2012; published online: 18 January 2013.

Citation: McDonald KL, Aw G and Kleihues $P$ (2013) Role of biomarkers in the clinical management of glioblastomas: what are the barriers and how can we overcome them? Front. Neur. 3:188. doi: 10.3389/fneur.2012.00188

This article was submitted to Frontiers in Neuro-oncology, a specialty of Frontiers in Neurology.

Copyright (c) 2013 McDonald, Aw and Kleihues. This is an open-access article distributed under the terms of the Creative Commons Attribution License, which permits use, distribution and reproduction in other forums, provided the original authors and source are credited and subject to any copyright notices concerning any third-party graphics etc. 